\title{
Measles outbreak investigation in a remote area of Solomon Islands, 2014
}

\author{
Jason Diau, ${ }^{a}$ Christopher Jimuru, ${ }^{a}$ James Asugeni, ${ }^{a}$ Lyndell Asugeni, ${ }^{a}$ Mike Puia, ${ }^{a}$ John Maomatekwa, ${ }^{a}$ \\ Humpress Harrington, ${ }^{b}$ David MacLaren, ${ }^{c}$ Rick Speare ${ }^{c d}$ and Peter D Masseye \\ Correspondence to Peter D Massey (email: peter.massey@hnehealth.nsw.gov.au).
}

Objective: To describe a measles outbreak and health service response in a remote location in Malaita, Solomon Islands.

Methods: Epidemiological review of cases who presented to the Atoifi Adventist Hospital (AAH) during the outbreak period from July to December 2014. Rumour surveillance was used to gather information on unreported cases.

Results: A total of 117 cases were reported to $\mathrm{AAH}$. The incidence rate was 123 per 10000 individuals. Fifty-six per cent $(66 / 117)$ of cases were hospitalized. Children under 5 years had the highest number of cases $(n=41)$ with 10 cases below 6 months old. The age-specific incidence rate of children under 5 years was 278.5 per 10000 individuals. Eighty-two per cent of reported cases were 18 years old or younger. Rumour surveillance revealed about three quarters of children in one area of the East Kwaio Mountains had suspected measles not reported to AAH. There were three unreported deaths from measles outside AAH. During the outbreak, a total of 2453 measles-rubella vaccines were given in the AAH catchment area.

Conclusion: A high incidence rate was observed in children and young people aged 18 years or younger, reflecting low childhood vaccination coverage. More than $50 \%$ of cases required hospitalization due to disease severity and challenges of accessing health services. The rumour surveillance discovered many unreported cases in the mountain areas and a few deaths possibly linked to the outbreak. Improvement of registration methods and follow-up systems and setting up satellite clinics are planned to improve measles surveillance and vaccination coverage.

$\mathrm{M}$ easles is a highly infectious, acute airborne viral disease with an infectious period of four days before to four days after rash onset. It has an incubation period of 10-14 days. Measles can be a serious illness with complications including otitis media, pneumonia and encephalitis. ${ }^{1}$

Solomon Islands lies between latitudes $6^{\circ}$ and $12^{\circ}$ and had a total population of 515870 in 2009. ${ }^{2}$ An outbreak of measles occurred in Papua New Guinea, Solomon Islands and Vanuatu during 2014. ${ }^{3}$ The first reported case of measles in Solomon Islands was a returned traveller from Papua New Guinea in July 2014. ${ }^{4}$ A total of 4563 cases with nine deaths were reported from across all 10 provinces in Solomon Islands. ${ }^{3}$ The highest incidence rate was reported in the Honiara area (349 per 10000 individuals) where there is good access to health services.
The first cases reported in the East Kwaio area of Solomon Islands were 1-year-old twins from a small village on 10 August 2014. The infants were not linked to the Honiara outbreak although there is frequent movement of small numbers of people between Honiara and East Kwaio. This report describes the local outbreak response and epidemiological investigation of the measles outbreak in East Kwaio.

\section{METHODS}

\section{Study site}

East Kwaio is on the eastern side of the island of Malaita of Solomon Islands (Figure 1 ). The population of East Kwaio was 9509 in 2009, 2,5 and most people live in coastal villages. Approximately 3000 people live in small hamlets in the mountainous area of Malaita and

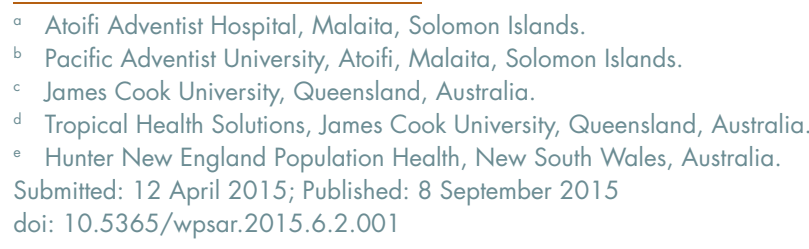


Figure 1. Map of East Kwaio, Solomon Islands

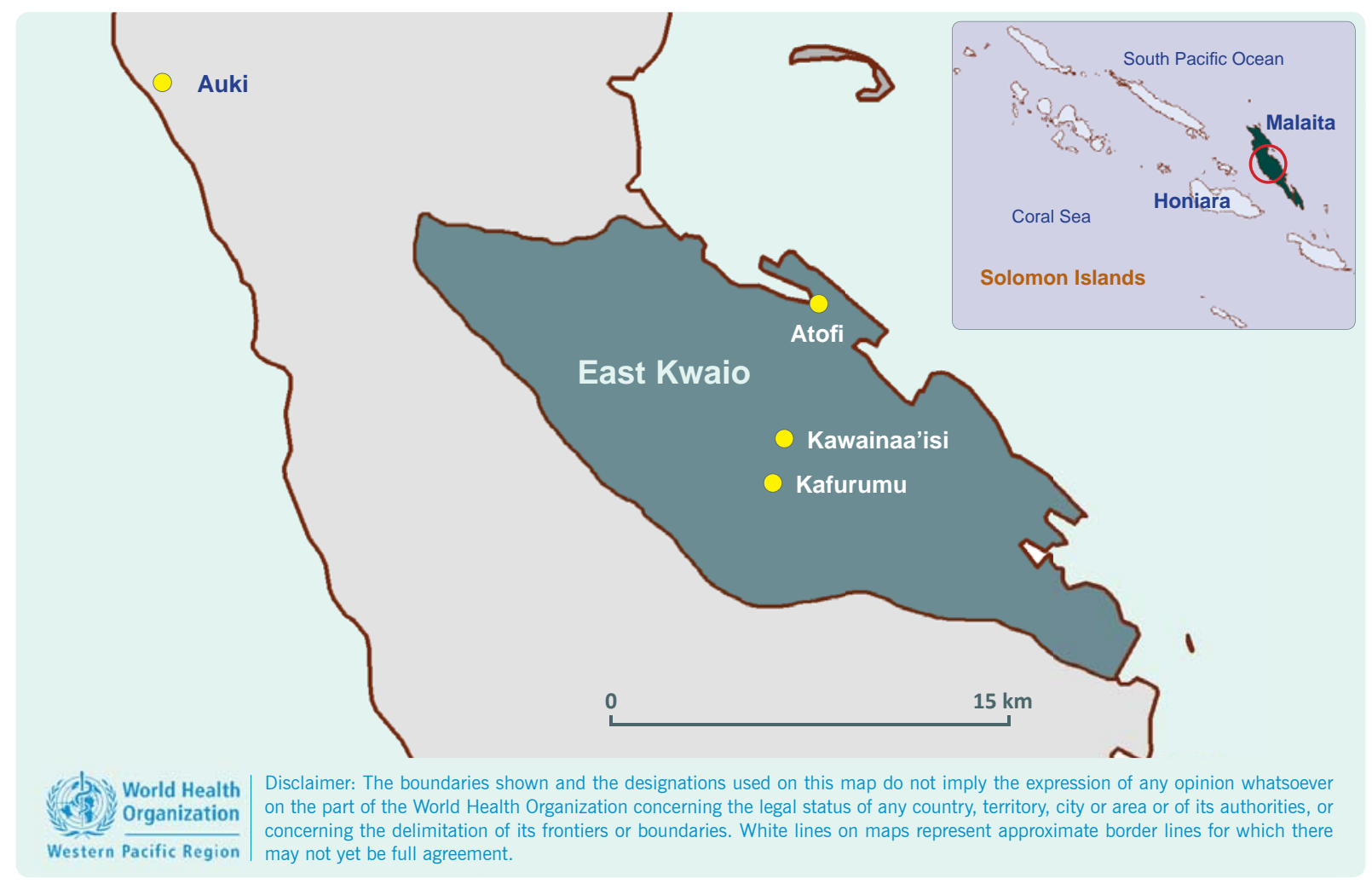

Notes: (1) Honiara is the capital of Solomon Islands; Auki is the provincial capital of Malaita; (2) Atoifi Adventist Hospital is located on the island of Malaita and serves mainly the East Kwaio area; and (3) the East Kwaio area comprises more than 40 villages and many mountain hamlets. Individual villages/hamlets are not shown due to the short distance between some villages and the temporary nature of some hamlets.

practise ancestral religion predominantly. ${ }^{6,7}$ There are no roads in East Kwaio. People have to walk or travel by canoe to Atoifi Adventist Hospital (AAH), the only hospital in the region.

\section{Case definition}

A measles case was defined as any person presenting to AAH between 1 August 2014 and 11 January 2015 with fever and maculopapular rash; and cough, coryza or conjunctivitis. ${ }^{8}$ Laboratory confirmations were not available at $\mathrm{AAH}$ or elsewhere in Malaita. Cases were diagnosed on clinical criteria only.

\section{Data collection, processing and analysis}

Demographics, location, onset, presenting symptoms, complications and hospitalization status of the cases were recorded. Case details were written in a record sheet and subsequently entered into and analysed by Microsoft Excel 2010. Incidence rates and relative risks with $95 \%$ confidence intervals $(\mathrm{Cl})$ were calculated based on the 2009 population census data. ${ }^{2,5}$

\section{Rumour surveillance}

Rumours were sought from community members who were visiting the hospital or attending local markets, through discussions with chiefs and from nursing staff at outreach clinics. Information on possible measles cases in the villages or hamlets was collected by staff and reported to the Outpatient Department and Primary Health Care (PHC) senior staff. Information was compiled into public health intelligence and used to guide action.

\section{RESULTS}

\section{Cases}

The outbreak occurred during epidemiological weeks 32 to 50 of 2014, with 117 total cases (Figure 2). Fifty per cent of cases were male; $82 \%$ were aged 18 years or younger. All reported cases (100\%) had fever and rash. Cough was reported by 90 (76.9\%) cases, and 89 (76.1\%) cases had conjunctivitis. The overall incidence rate for the $\mathrm{AAH}$ catchment 


\section{Figure 2. Number of measles cases presented to AAH, July to December 2014}

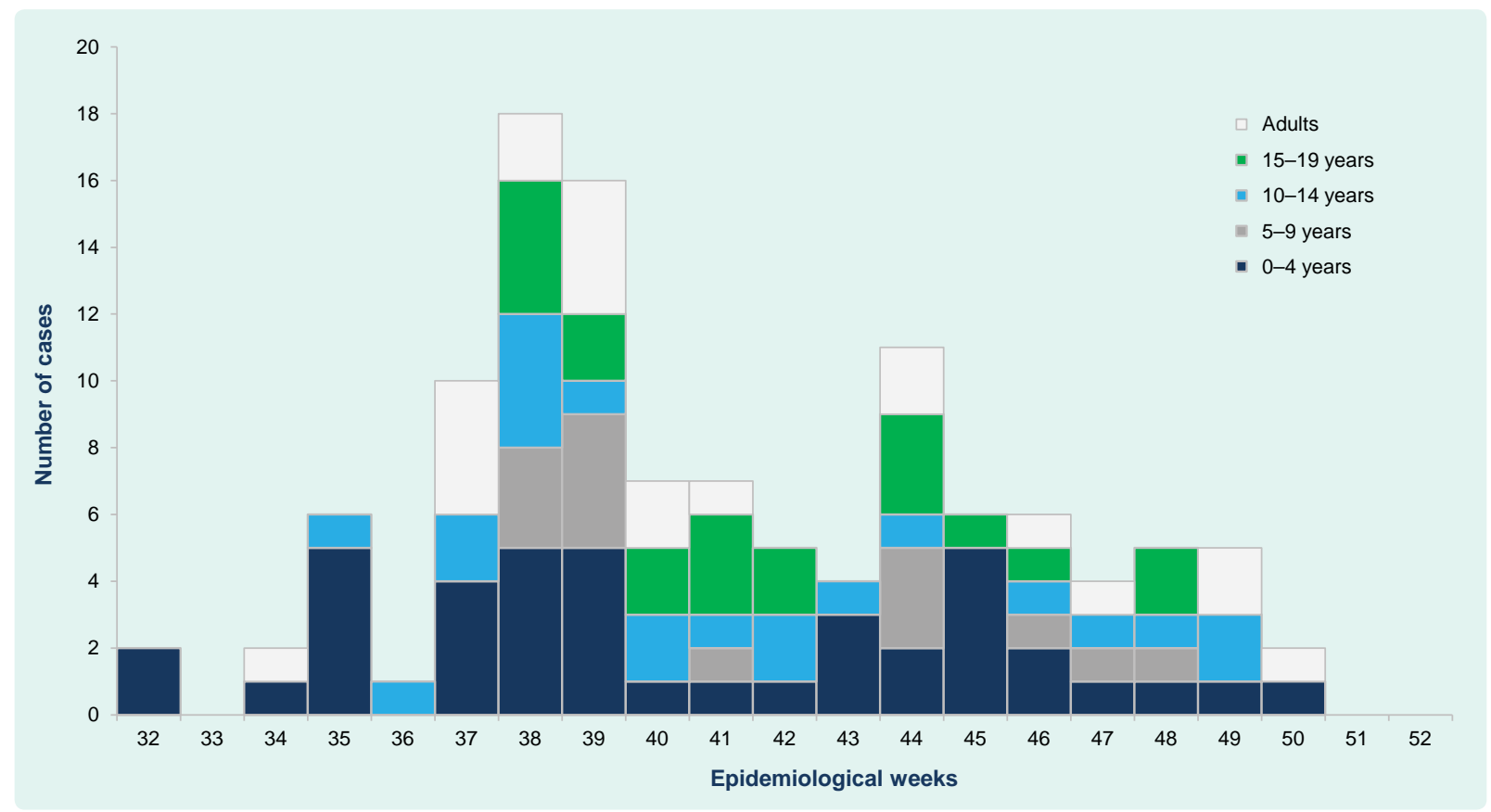

area was 123 per 10000 individuals with a relative risk of $2.88(95 \% \mathrm{Cl}: 2.36-3.50)$ compared to the rest of Malaita where 618 cases were reported in total (incidence rate 42.8 per 10000 individuals). ${ }^{3}$ The highest number of cases were found in the 0-4 years age group ( $n=41$ ) with 10 cases less than 6 months old. The age-specific incidence rate in this group was 278.5 per 10000 individuals.

Of the 117 cases, $66 \quad(56.4 \%)$ required hospitalization. Of these, $15.2 \%(10 / 66)$ and $18.2 \%$ (12/66) were under 1 year and 1 to 4 years, respectively. Eleven $(9.4 \%)$ of the cases were diagnosed with pneumonia. No other complications or deaths were reported.

Approximately $50 \%$ of the reported measles cases were from the mountainous areas of East Kwaio. Most of the villages (37/40) in the AAH catchment area reported cases. Kwalakwala village, with a population of 49 , had the highest attack rate $(38.8 \%, 19 / 49)$.

\section{Rumour surveillance}

Rumour surveillance indicated that there were only two suspected cases of measles in the mountains of the Karfurumu area. In the mountains of the Kwainaa'isi area, we estimated that three quarters of the 150 to 200 children and young people under age 19 had suspected measles but did not visit $\mathrm{AAH}$. There were also three deaths from measles reported in children from Kwainaa'isi that were not officially registered. However, these rumours were unable to be verified due to inaccessibility to the cases and sociocultural reasons.

\section{Measles outbreak response}

A local measles outbreak response team was formed on 24 August 2014. All residents of Atoifi were offered measles-rubella (MR) vaccination on 25 August. The remaining available vaccines were used on 26 August for children aged 6 months to 4 years in villages where a measles case had been reported (Canaan and Na'au) and in the four neighbouring villages. Rumour surveillance was initiated on 26 August 2014.

Alerts were sent to communities through hospital visitors and people attending the local markets. Measles cases attending the hospital were provided with a separate entrance and cared for in an isolation ward with restricted visitor numbers. Increased hand washing and the use of masks enhanced infection control in the hospital. Meanwhile, schools were not closed and community events continued to occur.

MR vaccination was offered to the family members of measles cases. Three teams of five nurses were deployed to conduct MR vaccination at the surrounding 
villages of East Kwaio. Children aged 6 months to 4 years were targeted in the first round followed by the schoolaged children (4 to 18 years) and adults older than 18 . A total of 2453 MR vaccines were given. We estimated a $73.5 \%(496 / 675)$ response for vaccination coverage of children aged 6 months to 4 years.

\section{DISCUSSION}

In the past 10 years, there have been only two published measles outbreak reports in Pacific islands (Marshall Islands and Fiji). These two reports mainly described national-level responses. ${ }^{9,10}$ Our report describes a measles outbreak in a remote area of Solomon Islands. We found the hospitalization rate was higher than the previously reported outbreak in the Pacific. ${ }^{9}$ Most cases presented with clinically apparent measles with rash and fever predominant. In remote settings, surge staff are not easily available for hospital care, and families are relied upon for much of the care of ill relatives. The sudden increase in admissions to a remote hospital like AAH can put significant demand on the staff and the facility.

Since the majority of the adult residents at Atoifi worked at $\mathrm{AAH}$, vaccinating all residents of Atoifi maintained the hospital's capability to manage the outbreak. On the other hand, for the villages that had not been rapidly vaccinated, a higher attack rate was observed. This may be linked to the two weeks delay in obtaining additional MR vaccines through the national programme.

The village of Kwalakwala had the highest attack rate among all villages (38.8\%). Many families in Kwalakwala village hold traditional beliefs that hinder measles vaccination. The AAH PHC team reported that before this outbreak, families in that area did not support vaccination. However, vaccination is now being promoted by the chiefs and elders due to the outbreak experience and the health promotion of the PHC team.

Rumour surveillance is a method that can be used to indicate the possible spread of a disease and areas to target for response. ${ }^{11}$ The results described many unreported cases in the mountainous areas and a few deaths possibly linked to the outbreak, though they were not verified. In addition to the long distance between home and hospital, there are complex sociocultural issues resulting in people from the mountains being unable to use health-care facilities. ${ }^{12}$ Many families also consult traditional healers for health advice first and delay their hospital visits. ${ }^{13}$

The high proportion of cases in children and the higher rates compared to other parts of Malaita, indicate that the vaccination coverage in East Kwaio had not been adequate to prevent outbreaks. In Solomon Islands, measles vaccination is scheduled at 12 months of age, mostly given by government services; the national coverage ranged from $60 \%$ to $80 \%$ in recent years. ${ }^{14}$ To increase and sustain the level of vaccination, the AAH has developed a range of new strategies. These strategies include a record card system to identify children overdue, enhanced registration of children into the primary health care system, providing more satellite clinics for remote villages/hamlets, implementing opportunistic vaccination at $A A H$ and satellite clinics and using rumour surveillance to identify and discuss vaccination with parents of children not born in the hospital. Information about children born in villages or hamlets can be found through chiefs and other community leaders and then used to direct outreach services.

Limitations of this report include that the case definition was not based on laboratory confirmation. Some cases may be misclassified. Passive surveillance with only certain levels of active case finding may miss some cases. There were no computerized data systems for data recording. Targeting of the outbreak response may not have been ideal for the local situation. ${ }^{15}$ Since this study only included cases who had visited $\mathrm{AAH}$, it may not be representative of all community cases. Vaccination status of the cases was not collected, which may have hampered further understanding of the outbreak.

\section{CONCLUSIONS}

The outbreak demonstrates that measles remains a threat in remote areas such as East Kwaio. This report highlights how sociocultural, geographic and health service issues contribute to the development and control of measles outbreaks and similar diseases.

\section{Conflicts of interest}

None declared. 


\section{Funding}

This outbreak investigation report also received some financial support from the TDR, the Special Programme for Research and Training in Tropical Diseases, cosponsored by United Nations Children's Fund, United Nations Development Programme, the World Bank and the World Health Organization (grant 1-811001688).

\section{Acknowledgements}

The authors would like to acknowledge and thank the following organizations for their support of this project and the ongoing work of improving health for the people of East Kwaio, Solomon Islands: Atoifi Adventist Hospital, Pacific Adventist University - Atoifi Campus, James Cook University and Hunter New England Population Health.

\section{References}

1. Heymann DL. Control of Communicable Diseases Manual 20th edition. Washington, DC, American Public Health Association, 2009, pp. 389-397.

2. Report on 2009 population and housing census: statistical bulletin 06/2011. Honiara, Government of Solomon Islands, 2011, p. 12 (http://catalog.ihsn.org/index.php/catalog/4595/ download/58455, accessed 29 July 2015).

3. World Health Organization Regional Office for the Western Pacific. Measles Outbreak, Solomon Islands, Health Situation Report No. 7. Geneva, ReliefWeb, 2014 (http://reliefweb.int/report/ solomon-islands/measles-outbreak-solomon-islands-healthsituation-report-no-7, accessed 29 July 2015).

4. World Health Organization. Health alert: suspected measles outbreak: Honiara, Solomon Islands, 23 July 2014. Geneva, Reliefweb, 2014 (http://reliefweb.int/report/solomon-islands/ health-alert-suspected-measles-outbreak-honiara-solomonislands-23-july-2014, accessed 29 July 2015).
5. Oloifana-Polosovai $\mathrm{H}$ et al. A marked decline in the incidence of malaria in a remote region of Malaita, Solomon Islands, 2008 to 2013. Western Pacific Surveillance and Response Journal, 2014, 5:30-39. doi:10.5365/wpsar.2014.5.3.002 pmid:25320674

6. MacLaren D, Kekeubata E. Reorienting health services through community health promotion in Kwaio, Solomon Islands. Promotion \& Education, 2007, 14:78-79. doi:10.1177/10253 823070140021701 pmid:17665704

7. MacLaren D et al. Incorporating sociocultural beliefs in mental health services in Kwaio, Solomon Islands. Australasian Psychiatry, 2009, 17(Suppl 1):S125-127. doi:10.1080/10398560902948381 pmid:19579125

8. WHO recommended standards for surveillance of selected vaccine-preventable diseases. Geneva, World Health Organization, 2003 (http://whqlibdoc.who.int/hq/2003/who_v\&b_03.01.pdf, accessed 29 July 2015).

9. Hyde TB et al. Measles outbreak in the Republic of the Marshall Islands, 2003. International Journal of Epidemiology, 2006, 35:299-306. doi:10.1093/ije/dyi222 pmid:16299123

10. Centers for Disease Control and Prevention (CDC). Measles outbreak and response-Fiji, February-May 2006. MMWR Morbidity and Mortality Weekly Report, 2006, 55:963-966. pmid: 16960551

11. Samaan G et al.; World Health Organization Outbreak Response Team. Rumor surveillance and avian influenza H5N1. Emerging Infectious Diseases, 2005, 11:463-466. doi:10.3201/ eid1103.040657 pmid:15757567

12. MacLaren D. Culturally appropriate health care in Kwaio, Malaita, Solomon Islands: an action research approach. PhD [dissertation]. Queensland, Griffith University, 2007.

13. Massey PD et al. TB questions, East Kwaio answers: community-based participatory research in a remote area of Solomon Islands. Rural and Remote Health, 2012, 12:2139. pmid:23094978

14. Immunization epi country poster. Manila, World Health Organization Regional Office for the Western Pacific, 2010 (http://www.wpro.who.int/immunization/documents/epi_country_ poster_2010_SOL.pdf?ua=1, accessed 29 July 2015).

15. Minetti A et al. Measles outbreak response immunization is contextspecific: insight from the recent experience of Médecins Sans Frontières. PLoS Medicine, 2013, 10:e1001544. doi:10.1371/ journal.pmed.1001544 pmid:24223523 